\title{
Managing visitors in nature areas: where do they leave the trails? A spatial model
}

\author{
Joy Coppes \& Veronika Braunisch
}

Outdoor recreation, particularly in winter, causes pressure on wildlife. While many species seem to adjust well to predictable on-trail recreation activities, unpredictable off-trail activities are considered harmful. Measures to minimise human disturbance require the identification of 'conflict-sites' where human activities are likely to interfere with the requirements of wildlife. We used winter recreation data combined with spatial modelling to predict where recreationists move from marked trails into wildlife habitats in winter and to determine the environmental factors that trigger this offtrail behaviour. We surveyed marked winter trails in the southern Black Forest, Germany, by foot or ski for tracks of people leaving the trail, with three types of recreationists distinguished: hikers, snowshoe users and cross-country skiers. Using a maximum entropy approach, the probability of leaving the trail was modelled as a function of topographic, forest structure and tourism infrastructure variables. By combining the results with previously mapped habitat information of two disturbance sensitive species, the capercaillie Tetrao urogallus and the red deer Cervus elaphus, we identified conflict sites where mitigation measures would be most effective. All models were effective in predicting the locations where people left the trails and the three types of recreationists showed a similar pattern: the presence of closed summer trails and signposts along these trails proved to be the factors most strongly affecting the probability of leaving marked trails, followed by slope, which was negatively correlated with the probability of going off-trail. People leaving directly into the forest, not using a summer trail, were most positively influenced by the successional stages 'regeneration' and 'old forest', whereas increasing canopy cover decreased the probability of leaving the trail. The models were extrapolated to all marked trails in the study area. Locations with a high probability of people leaving the trails were identified and intersected with the previously mapped key habitats of the two wildlife species, thereby showing the locations where leaving the trail would be linked with a high potential of human-wildlife conflict. By indicating what triggers people to leave the trails, and identifying the critical locations, our results contribute to the determination of adequate management measures.

Key words: human-wildlife conflict, human disturbance, Maxent, off-trail recreation, tourism, visitor steering, wildlife management

Joy Coppes, Forest Research Institute of Baden-Wuerttemberg FVA, Wildlife Ecology Division, Wonnhaldestraße 4, D79100 Freiburg, Germany, and Van Hall-Larenstein University of Applied Sciences, Agora 1, NL-8934 CJ Leeuwarden, The Netherlands-e-mail: Joy.Coppes@forst.bwl.de

Veronika Braunisch, Forest Research Institute of Baden-Wuerttemberg FVA, Wildlife Ecology Division, Wonnhaldestraße 4, D-79100 Freiburg, Germany, and Conservation Biology, Institute of Ecology and Evolution, University of Bern, Baltzerstraße 6, CH-3012 Bern, Switzerland-e-mail:Veronika.Braunisch@forst.bwl.de

Corresponding author: Joy Coppes

Received 21 May 2012, accepted 26 September 2012

Associate Editor: Anthony P. Clevenger

Outdoor tourism and recreation activities are growing and are expected to continue to grow in the future (UN 2001, Eagles et al. 2002, Hennig \& Künzl 2011), thereby causing increasing pressure on nature and wildlife worldwide (UN 1999, UNEP 2007). The presence of the increasing number of people outdoors can have serious impacts on ecosystems and wildlife (UNEP 2007). Adequate visitor management to reduce the effects of this pressure thus becomes more and more important (Hennig \& Künzl 
2011). The response of free-ranging animals to human presence can range from direct behavioural responses (Fernández-Juricic \& Telleria 2000, Beale \& Monaghan 2004) that affect predation risk, energy intake and energy expenditure of the animal (Cassirer et al. 1992, Baltic 2005), to stress responses (Arlettaz et al. 2007, Thiel et al. 2008), and retreat of the animals from otherwise suitable habitats to suboptimal zones (Taylor \& Knight 2003, Thiel et al. 2008, Patthey et al. 2008). All of these responses can have direct fitness costs (Moss \& Watson 1984, Müllner et al. 2004, Watson \& Moss 2004, Amo et al. 2006). Human disturbance (defined here as human activities triggering the above-mentioned responses) is considered to be particularly problematic for wildlife in winter when food is limited and additional energy expenditures cannot be sufficiently compensated. Moreover, some winter outdoor activities, such as back-country skiing and the increasingly popular snowshoeing, are usually conducted off-trail. In contrast to on-trail activities which allow habituation (Yarmoloy et al. 1988, Miller et al. 2001), wildlife species can hardly adjust to off-trail disturbances (Geist 1978, Miller et al. 2001) with the greater impact reflected by larger flushing distances, i.e. the distance in which the animals react to the presence of humans (Miller et al. 2001, Taylor \& Knight 2003, Thiel et al. 2007). In the densely inhabited landscapes of Central Europe there is often not enough space to meet the demands of outdoor sporting activities and to ban sports from protected areas at the same time (Türk et al. 2004). Consequently, outdoor activities will largely continue to be practised in, or close to, protected areas (Türk et al. 2004), which makes it increasingly important to effectively manage visitor flows to comply with the needs of humans and wildlife (Hennig \& Künzl 2011). Unmanaged or poorly managed outdoor activities can have serious impacts on ecosystems and their biodiversity and can even be a major cause for species endangerment (Czech 2000, Yorio et al. 2001, UNEP 2007). Yet, effective visitor management requires precise and accurate information on visitor behaviour (Watson et al. 2000, Cessford \& Muhar 2003, Cole \& Daniel 2003, Hennig \& Künzl 2011), which is frequently not available or "based on verbal reports of visitors, best guesses by area managers or, typically, rough estimates" (Arnberger \& Hinterberger 2003). To design adequate measures for minimising human disturbance, the identification of human-wildlife conflict areas is crucial (Hennig \& Künzl 2011). Yet, there is a lack of applicable methods to assess unpredictable, free-ranging activities directly. Traditional research based on visitor interviews has the disadvantage that answers might not be truthful (Nisbitt \& Wilson 1977, Cole \& Daniel 2003). Statistical models predicting human activities and their interference with wildlife key habitats are thus beneficial for conservation purposes (Braunisch et al. 2011) and a valuable tool for management (Cole \& Daniel 2003, Cole 2004). However, gathering area-wide information about the spatial distribution of off-trail activities, without causing additional disturbance while sampling, is difficult. In our study, we focussed on identifying the locations where recreationists leave the marked trails in winter to continue their activity off-trail by using a sampling method that minimises disturbance to wildlife, in combination with spatial modelling. Assuming that most people with the intention of going off-trail in areas with a dense infrastructure network will reach the area by leaving an existing trail, particularly under winter conditions, the prediction and management of these crucial locations would represent a cost-effective option compared to area-wide surveys. Therefore, our main goals were to 1) predict where people leave marked trails, 2) determine which environmental factors prevail at the locations where people leave the trails, and 3) identify conflict sites between those who go off-trail and wildlife by using the example of two disturbance-sensitive species: the capercaillie Tetrao urogallus and the red deer Cervus elaphus.

\section{Material and methods}

\section{Study area}

Our study was conducted in the southern part of the Black Forest, a lower mountain range located in southwestern Germany. The study area of about 9,000 ha encompasses the Feldberg mountain and lake Schluchsee: two famous tourist destinations. The elevation in the study area ranged between 1,000 and $1,400 \mathrm{~m}$ a.s.1., and $66 \%$ of the area was covered by managed forests that are dominated by Norway spruce Picea abies (49\%), European silver fir Abies alba $(19 \%)$ and common beech Fagus sylvatica (22\%; Suchant et al. 2003). Recreation in winter is diverse, ranging from intensively used skiing resorts with downhill ski runs, hiking and cross-country skiing trails to predominantly recreation-free forests. The area offers a dense network of trails for recreation and forestry services. Most trails are open for recreational purposes during summer, but many 
of these are closed to the public in winter with the aim of reducing disturbance to wildlife. Within our study area, marked trails for winter recreation amounted to a total length of $110 \mathrm{~km}$. On the most intensively used trails, an average of 230 visitors/day during weekends of the study season were counted using photo sensors (F. Burghardt, unpubl. data). Off-trail activities such as snow-shoeing and back-country skiing have become increasingly popular and frequent in the study area in the last few years (Thiel et al. 2008).

Large parts of our study area are part of Natura 2000 sites (European Commission 2000), with the red-listed capercaillie as a major subject of protection (Braunisch \& Suchant 2006). The area around the Feldberg mountain holds one of the largest subpopulations of capercaillie in the Black Forest. The lake Schluchsee area is a red deer management area with regulations for hunting, recreation and forestry, and has zones designated as red deer refuges and winter feeding areas (Suchant et al. 2008). Red deer and capercaillie are considered to be highly sensitive to spatially and temporally irregular disturbances (Reimoser 1988, Thiel et al. 2007) and show stronger reactions to off-trail recreationists compared to people moving on trails, as reflected by larger flushing distances (Reimoser 1988, Thiel et al. 2007, Jayakody et al. 2008).

Both species react similar to recreationists as to predators, with increased vigilance and fleeing behaviour (Thiel et al. 2007, Jayakody et al. 2008, Stankowich 2008). These reactions increase their energy expenditure or reduce the energy intake, thus having direct fitness costs (reviewed in Stankowich 2008). For capercaillie, winter recreation has additionally been shown to result in both home-range displacement as well as increased corticosterone basal levels (Thiel et al. 2008), and throughout Central Europe recreation is considered a "serious threat" to local capercaillie populations (Storch 2000, 2007a, b).

\section{Delineation of sensitive wildlife areas}

Areas with high importance to capercaillie and red deer were determined to identify sites where leaving marked trails would counteract the goals of wildlife management. Capercaillie are considered susceptible to human disturbance (Thiel et al. 2008, Hennig \& Künzl 2011), especially in winter. Therefore the entire distribution of capercaillie within our study area, which has been mapped every five years based on long-term direct and indirect observations of capercaillie collected by a wide network of ornithologists, hunters and foresters (Braunisch \& Suchant
2006), has been classified as a 'sensitive area' for this species.

Red deer, when undisturbed, may lower their metabolic rate in winter (Arnold et al. 2004), which results in lower energy needs and therefore lower feeding rates and less damage to forestry. To reduce conflicts with the interests of forestry, red deer are fed in winter, which concentrates the animals in small areas. Problems occur when the deer are disturbed at these feeding sites, as they will then spread out and cause more damage in the surrounding area (Ingold 2005). Sensitive areas for red deer were thus defined as the refuge and feeding areas designated in the management plan (Suchant et al. 2008).

\section{Data collection}

\section{Off-trail activities}

Data on winter recreation were collected two to five days after fresh snowfall, from December 2009 to March 2010. We surveyed 15 marked winter-trails, with a total length of $110 \mathrm{~km}$ (in the following referred to as 'sampling trails') four to five times with a minimum of four days between surveys, on foot or skis for tracks of hikers, snowshoe users and crosscountry skiers leaving the trail. We followed tracks up to $50 \mathrm{~m}$ to determine whether the person left the trail to continue the journey off-trail, or whether the person returned to the marked trail. We collected data on location, direction and type of tracks. Once tracks had been recorded, we erased them to prevent double counting and to remove their potential to influence later parties to leave the trail in the same place.

\section{Environmental data}

We tested the variables for their influence on people leaving the sampling trails including information on topography (slope), vegetation and recreation infrastructure ('trail signs'; Table 1) and assessed the variables within a $100-\mathrm{m}$ buffer zone to both sides of the trail. Our working hypothesis was that shallow slopes, open vegetation and signs of summer recreation infrastructure would encourage off-trail behaviour.

We derived slope from a digital elevation model (Land survey office, Baden-Württemberg). Vegetation structure was adopted from mappings at the forest-stand level conducted in 2005 and included cover, type of canopy and undergrowth, and the succession stage as defined in Table 1.

As an indicator of recreation infrastructure, the 
Table 1. Variables tested in the models.

\begin{tabular}{|c|c|c|}
\hline Variable & Type & Range/categories \\
\hline Trail signs & Categorical & $\begin{array}{l}0=\text { no road } \\
1=\text { road without sign } \\
2=\text { road with name sign } \\
3=\text { road with direction sign }\end{array}$ \\
\hline Canopy type & Categorical & $\begin{array}{l}0=\text { open area } \\
1=\text { coniferous }(>95 \%) \\
2=\text { deciduous }(>95 \%) \\
3=\text { mixed forest }\end{array}$ \\
\hline Canopy cover & Continuous & $0-100 \%$ \\
\hline Succession stages & Categorical & $\begin{array}{l}0=\text { open area }(\text { no trees }) \\
1=\text { regeneration } \\
2=\text { thicket }\left(\mathrm{DBH}^{\mathrm{a}}<15 \mathrm{~cm}\right) \\
3=\text { pole stage }\left(\mathrm{DBH}^{\mathrm{a}}>15 \mathrm{~cm},<20 \mathrm{~cm}\right) \\
4=\text { tree stage }\left(\mathrm{DBH}^{\mathrm{a}}>20 \mathrm{~cm},<50 \mathrm{~cm}\right) \\
5=\text { old forest }\left(\mathrm{DBH}^{\mathrm{a}}>50 \mathrm{~cm}\right)\end{array}$ \\
\hline Undergrowth type & Categorical & $\begin{array}{l}0=\text { no undergrowth } \\
1=\text { coniferous } \\
2=\text { deciduous } \\
3=\text { mixed forest }\end{array}$ \\
\hline Undergrowth cover & Continuous & $0-100 \%$ \\
\hline Slope & Continuous & $0-50 \%$ \\
\hline
\end{tabular}

$\mathrm{DBH}^{\mathrm{a}}$ : Tree diameter at breast height

variable 'trail signs' was mapped during our study and refers to closed trails (e.g. forestry and summer trails). These trails are not cleared of snow and are closed for public use in winter, which is indicated by information boards in our study area. The closed trails were not individually marked by a prohibition sign, but some were marked with signs indicating either the name of the trail and/or a destination for use in summer. The closed trails and all signposts along the sampling route were mapped and were then classified into three categories: 1) without sign, 2) with name sign and 3) with destination sign. Trails with both types of signs were assigned to category 3 . All variables were prepared as ArcGIS 9.2 raster maps with a cell size of $10 \times 10 \mathrm{~m}$.

We assumed that people would be influenced by the environmental conditions prevailing within a perception range of up to $100 \mathrm{~m}$ in the direction they would leave the trail. To include only the conditions at the respective side of the trail in the analysis, the track locations were moved $50 \mathrm{~m}$ in the direction of the tracks (Fig. 1), then all variables were assessed within a 50-m radius (neighbourhood statistics, ArcGIS 9.2) calculating the average for continuous variables and the majority within this 50-m radius for categorical variables.

\section{Data analysis}

\section{Model generation}

We analysed the data using a machine-learning approach, which is based on the principle of maximum entropy (Jaynes 1957). This approach has been widely used in many fields of computer science and statistical learning (Berger et al. 1996, Della Pietra et al. 1997) and, implemented in the program MAXENT (version 3.3.2; Phillips et al. 2006), is frequently

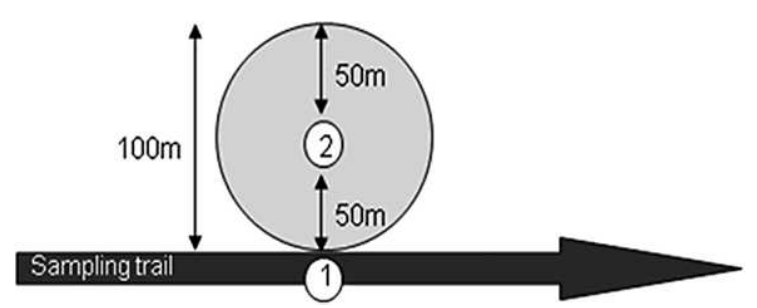

Figure 1. Sampling range of the environmental variables. At location 1, a person left the sampling trail to the left; for the data analysis this location was moved $50 \mathrm{~m}$ along the walking direction to location 2. Environmental variables were analysed within a 50-m radius (light grey area) around this location. 
employed to model the distribution of plant and animal species, where a similar performance compared to discrete choice and logistic regression models has been shown (Baasch et al. 2010). MAXENT is considered to be one of the best methods to model species distributions when reliable absence data are missing (Elith et al. 2006, Dudik et al. 2007, Phillips \& Dudik 2008, Braunisch \& Suchant 2010) and was chosen in our study because an absence of observations during the sampling walks on tracks of persons leaving the trail at a particular location cannot be interpreted as proof that people never go off-trail at that location.

MAXENT compares the environmental conditions at the occurrence locations with those prevailing in the area defined as 'available', using an iterative process to generate a spatial probability distribution across our study area, which can be interpreted as the relative probability of occurrence (Jepsen et al. 2011) or, in this case, as the probability that people leave the trail at a specific location with the 100-m buffer on both sides of the sampling trails defined as the area available for leaving the trail. As predictors, the raw environmental variables as well as functions thereof ('features') are used. Each feature is weighted with a coefficient which is iteratively changed until the resulting probability distribution maximises the likelihood of the occurrence data (Phillips \& Dudik 2008). We used linear, quadratic and product features as well as threshold and hinge features to allow for interactions between variables or influential thresholds in a variable's range. Different models were calculated for each of the three different recreation types, skiers (M1), hikers (M2) and snowshoe users (M3), and for the pooled data of all types (M4). In addition, the latter model was recalculated using only tracks of recreationists directly leaving into the forest (M5), i.e. excluding locations where persons left marked trails to continue on closed summer trails. A jackknife procedure was performed, leaving out each variable in turn, to quantify its contributions to the model. In addition, we calculated and graphed the response by plotting the probability of off-trail behaviour as a function of each variable, while holding all the other variables at their average sample value. The models were run using a maximum of 500 iterations and a convergence threshold of $10^{-5}$.

\section{Model evaluation}

The models were evaluated using a 10 -fold cross validation. To determine the predictive power, we calculated the area under the receiver operating characteristics curve (AUC), which is obtained by plotting sensitivity versus 1-specificity for all possible binary classifications of predicted presence and absence, as the discrimination threshold is varied. In our case, i.e. with no reliable absence data available to determine specificity, we calculated the AUC using a representative number of random locations instead, and therefore it must be interpreted as the models' ability to discriminate between 'presence' and 'random' rather than between presence and absence (Wiley et al. 2003, Phillips et al. 2006). AUC values exceeding 0.5 indicate models that predict better than random, while an AUC $\geq 0.7$ is generally considered acceptable, $\geq 0.8$ as good and $\geq 0.9$ as excellent (Swets 1988, Hosmer \& Lemeshow 2000).

In addition, separate models of M4 (using the data of all recreation types combined) were calibrated for the two subareas 'Feldberg' and 'Schluchsee', and the model from each region was used to predict the spatial distribution of off-trail activities in the other, which allowed testing the models' spatial transferability.

\section{Identification of conflict-locations}

The resulting probability distributions were classified into three classes: low $(\mathrm{P}<0.25 \%)$, medium $(0.26<$ $\mathrm{P}<0.5 \%)$ and high $(\mathrm{P}>0.5)$ probability of leaving the trail. The results were intersected with the sensitive wildlife areas as previously defined (i.e. capercaillie areas and red deer refuges) and locations where a high probability of leaving the trail spatially coincided with a sensitive area (e.g. a person leaving at this location would directly enter a sensitive wildlife area) were classified as 'conflict situations' between wildlife and off-trail recreationists.

\section{Results}

We found a total of 484 tracks of people leaving the trails. Of these, 120 were attributed to hikers, 149 to cross-country skiers and 215 to snowshoe users.

\section{Models}

The mean AUC values of the models ranged between 0.80 (cross-country skiers) and 0.71 (hikers; Table 2). The variable 'trail signs' contributed by far the most (81.3-75.5\%) to all models, except to the model in which this parameter was excluded (M5). The probability of leaving the track increased when a trail was available, and even more when a name sign was present, and was highest when the sign indicated 
Table 2. Mean and standard deviation of AUC (SD) of the individual models (calculated from 10 cross-validation replicates), and variables' contributions given in percent contribution to the total increase in regularised Log-likelihood of the Maximum Entropy model.

\begin{tabular}{|c|c|c|c|c|c|}
\hline Model & M1 & M2 & M3 & M4 & M5 \\
\hline $\begin{array}{l}\text { Recreation type } \\
\text { (sample size) }\end{array}$ & $\begin{array}{l}\text { Cross-country skiers } \\
\qquad(\mathrm{N}=149)\end{array}$ & $\begin{array}{c}\text { Hikers } \\
(\mathrm{N}=120)\end{array}$ & $\begin{array}{l}\text { Snowshoe users } \\
\quad(\mathrm{N}=215)\end{array}$ & $\begin{array}{l}\text { All sport types } \\
\qquad(\mathrm{N}=484)\end{array}$ & $\begin{array}{c}\text { All types tracks } \\
\text { directly leaving } \\
\text { into the forest } \\
(\mathrm{N}=249)\end{array}$ \\
\hline $\mathrm{AUC}^{\mathrm{a}}(\mathrm{SD})$ & $0.80(0.04)$ & $0.71(0.05)$ & $0.76(0.04)$ & $0.78(0.02)$ & $0.74(0.02)$ \\
\hline \multicolumn{6}{|c|}{ Varibale contribution (in \%) } \\
\hline Trail signs & 75 & 81 & 75 & 81 & - \\
\hline Slope & 14 & 3 & 8 & 8 & 14 \\
\hline Succession stage & 5 & 5 & 4 & 3 & 40 \\
\hline Undergrowth type & 2 & 3 & 2 & 2 & 6 \\
\hline Canopy cover & 2 & 1 & 3 & 2 & 20 \\
\hline Undergrowth cover & 0 & 1 & 2 & 1 & 7 \\
\hline Canopy type & 0 & 2 & 3 & 0 & 10 \\
\hline
\end{tabular}

${ }^{a}$ Mean area under the receiver operating characteristics curve based on 10 cross-validation replicates.

a destination (Fig. 2A). 'Slope' was the second most important contributing variable $(8.0-14.0 \%)$ for all the models that included the full variable set (M1-4), with the exception of the model for hikers (M2). The probability of leaving the trail decreased strongly when the terrain around the trail was steeper (see Fig.
2B). The variable 'succession stage' was among the three most important predictors in all models, with the highest probabilities of persons leaving the trail associated with the succession stages 'regeneration' and 'old forest' (see Fig. 2C). The model in which the 'trail signs' parameter was excluded (M5) showed
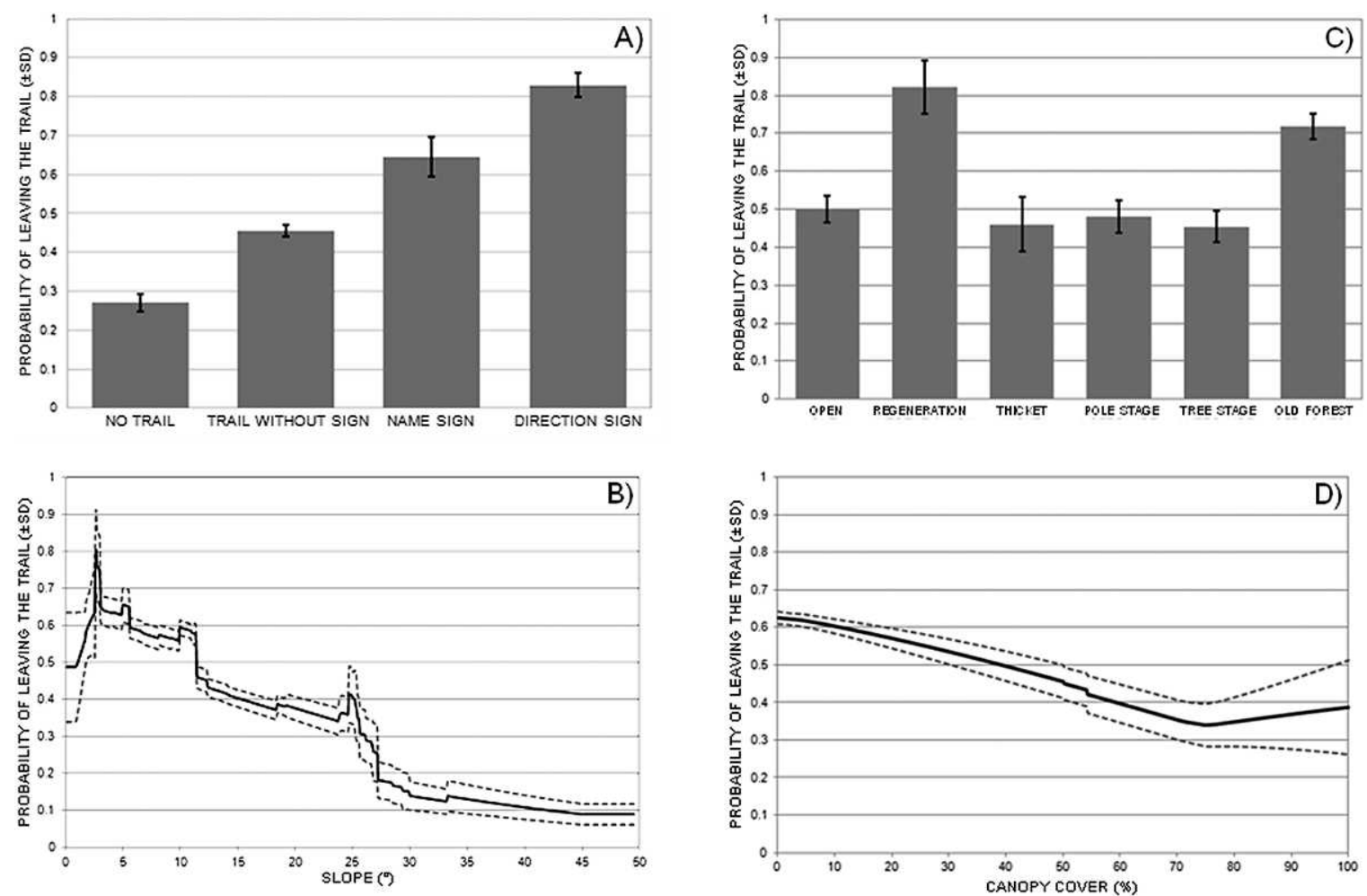

Figure 2. Response curves and graphs, showing the probability of leaving the trail in dependence of the variables 'trail signs' (A) and 'slope' (B) in M4 (see Table 2), and the effect of 'succession stage' (C) and 'canopy cover' on the probability of leaving the trail directly into the forest M5 (D). 
this variable to be the most important with $40.6 \%$ contribution. 'Canopy cover' was also an important predictor in M5, with $20.8 \%$ contribution. With increasing canopy cover the probability of leaving the trail decreased until a threshold cover of $75 \%$, subsequently showing a slight increase until 100\% canopy cover was reached (see Fig. 2D).

\section{Spatial validation}

The spatial validation showed a generally good transferability, i.e. the predictive model calibrated in the 'Schluchsee-area' predicted off-trail behaviour in 'Feldberg' with an AUC of 0.716. The AUC of the 'Feldberg model' tested in the 'Schluchsee' area was 0.769 .

\section{Conflict locations}

Since the different types of recreationists showed similar behaviour, the pooled data of all types were used to predict conflict locations. According to model M4, there was a high probability of people leaving the trail in $8.5 \%$ of the area, whereas medium and low probabilities prevailed in $32.4 \%$ and $59.1 \%$, respectively (Fig. 3). A total of six conflict locations were found when intersecting the 'high probability sites' with the red deer feeding and refuge areas. With regard to the capercaillie habitats, a total of 56 conflict situations were found and several of these were located relatively close to each other (Fig. 4). When considering only people who would leave the trail directly into the forest (e.g. not using a closed trail), a larger area with a high probability of people leaving the trail $(27.5 \%)$ was identified. The area with medium probability of leaving the trail was similar to the other model in which 'trail signs' were included $(34.6 \%)$, whereas there was less area where the probability was low $(37.9 \%)$.

\section{Discussion}

Information about the spatial distribution and intensity of recreation activities is a crucial prereq-

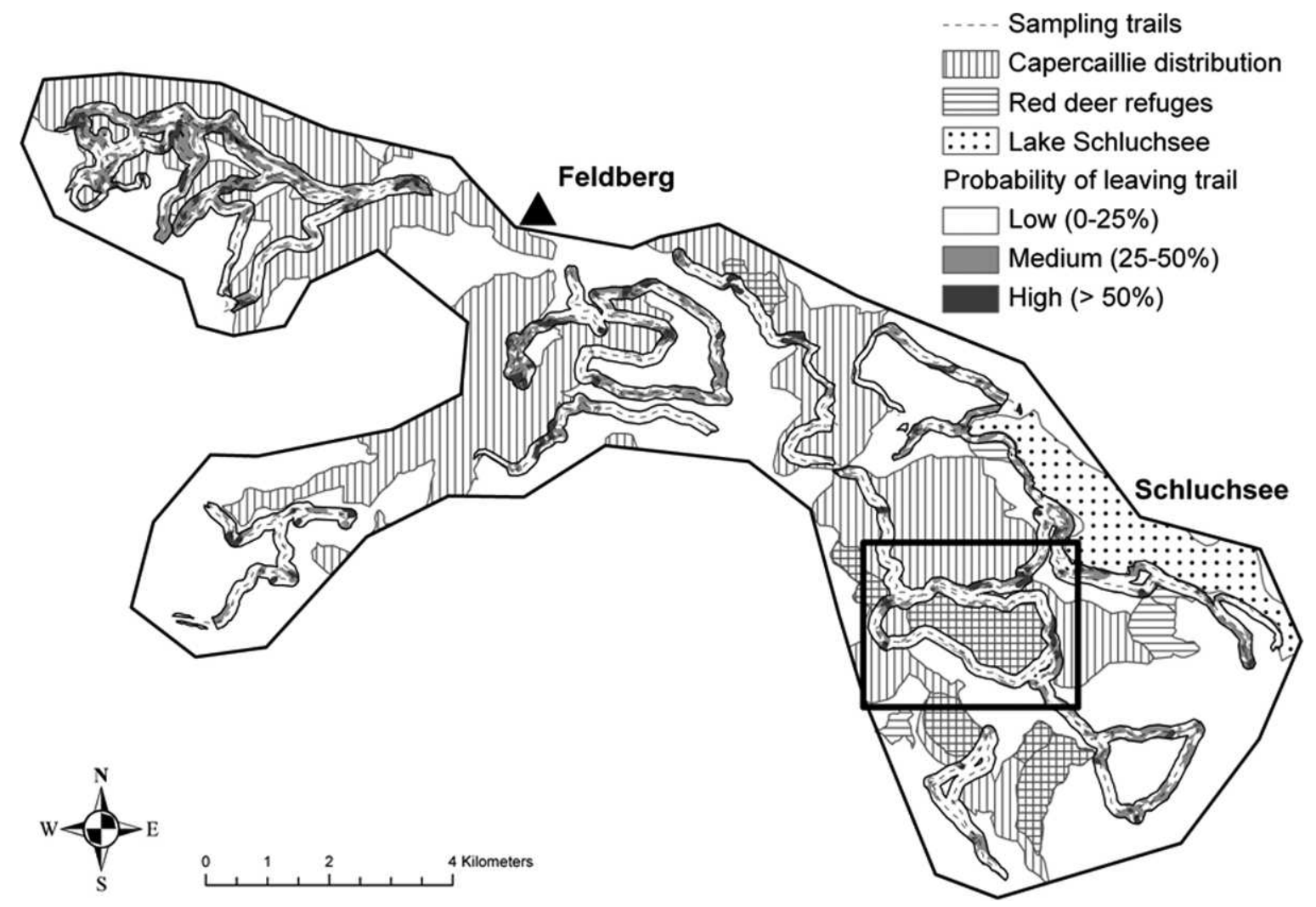

Figure 3. Sampling trails within our study area and the probability of leaving the trail resulting from model 4, classified as high, medium and low probability, predicted within a 100-m buffer zone to both sides of the trail. The sensitive wildlife areas for both species (capercaillie and red deer) combined, are marked with both horizontal and vertical lines. The black square indicates the example region for which conflict sites are shown in Figure 4. 
Figure 4. Detailed view of the example region (indicated in Fig. 3) showing the conflict sites (stars), defined as sites with a high probability of people leaving the trail (model 4) into 'sensitive wildlife areas', i.e. red deer refuges (horizontal lines) or capercaillie habitats (vertical lines).

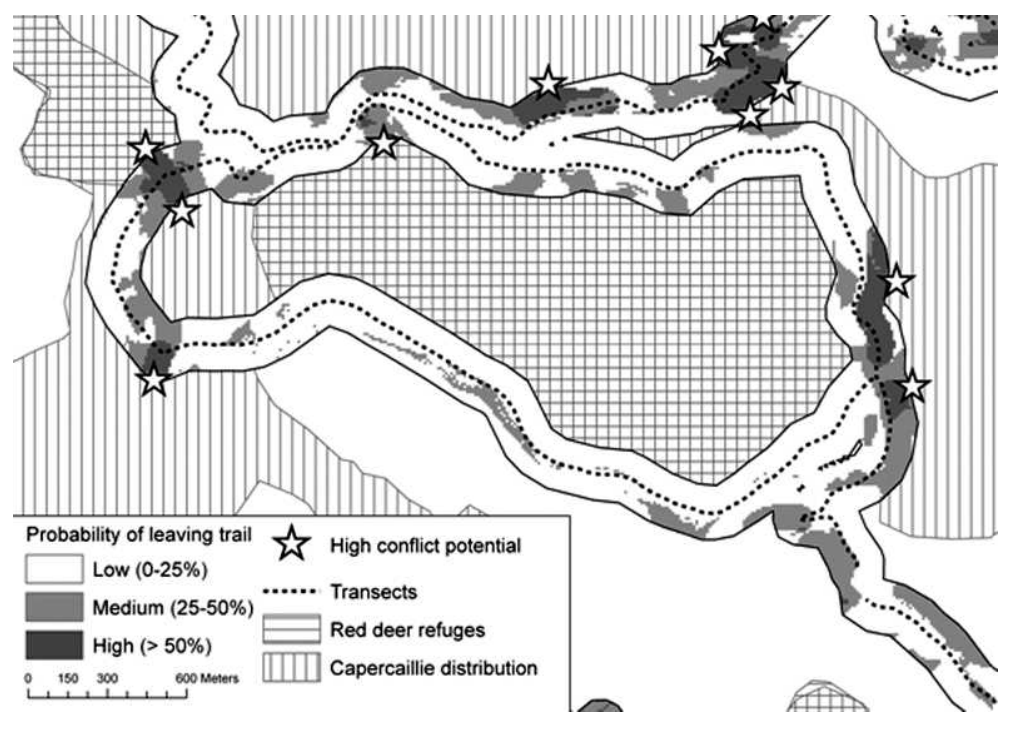

uisite for effective visitor management in nature areas (Watson et al. 2000, Cessford \& Muhar 2003, Cole \& Daniel 2003, Hennig \& Künzl 2011). Our results support former studies (e.g. Braunisch et al. 2011) showing that it is possible to predict human off-trail behaviour by using spatial-distribution modelling. With an AUC $>0.7$, all our models were effective in predicting locations where people leave the marked trails and, by testing their spatial transferability, proved suitable to be extrapolated to other areas in the Black Forest.

'Trail signs' was the variable that triggered off-trail behaviour most. If a trail with a direction or name sign was available, the probability increased that people would leave the trail at this point, even if the trail was closed. This result is consistent with previous studies that have shown that the majority of people leave trails along linear routes and unmaintained track ways (Keirle \& Stephens 2004). Park et al. (2008) found that direct management interventions, such as fencing a trail entrance, are a more effective method for keeping visitors on trails than informing the public by using prohibition signs. This study showed that deviation from trails is reduced when name and destination signs are absent, so Park et al.'s (2008) interventions may be enhanced by removing or covering navigational signs in winter and thus further reducing the number of visitors leaving the open trails. Furthermore, when a track is not needed for forestry or for summer recreation, managers of natural areas could consider blocking the track entirely.

The most important factor influencing visitors who leave the trails directly into the forest was the succession stage, with the highest probability of persons going off-trail found where the bordering forest was at the stages 'regeneration' and 'old forest'. Both categories are characterised by rather open forest structures that are easily accessible. To reduce the number of visitors leaving the trail into such forest stands, a narrow band of dense vegetation, such as thickets or pole stages, could be maintained along the trails at locations where people could enter a sensitive wildlife area. Thiel et al. (2007) also suggest this as an adequate measure for reducing the flushing distance of capercaillie close to recreational trails, by decreasing the visibility of the recreationists.

The different recreation types (e.g. hiking, snowshoeing and cross-country skiing) seem to behave relatively similarly in the Black Forest. This indicates that a single management approach could be used to reach all groups. Since the recreationists' behaviour is mostly affected by the availability of trails and signs, management can focus on these specific factors. One should be careful though to extrapolate these results to other areas with different landscape characteristics and tourist types. The Black Forest has a dense network of trails and forestry roads and slopes are relatively shallow compared to Alpine environments, where a similar behaviour was observed for snowshoe users, whereas the skiers' spatial patterns differed considerably (Braunisch et al. 2011). Environmental conditions (e.g. snow depths and slope) outside the investigated range might affect recreationists differently, so the behaviour of the recreation types might diverge more under other conditions. 
Area-wide, spatially explicit modelling of off-trail behaviour requires representative sampling across large areas (Braunisch et al. 2011), which is linked with a high sampling effort and may cause considerable disturbance. Particularly in landscapes with a dense network of trails, rather than taking area-wide measures, it can thus be more efficient to identify the locations where people would leave the marked trails, and to apply interventions at these crucial sites such as blocking trail heads, covering signposts or installing information panels. Our approach does not depend on costly data (e.g. aerial photographs) but used relatively inexpensive methods for assessing both visitor behaviour and environmental conditions. Most of the vegetation data may be obtained from regular forestry maps, the collection of the other information is simple and not time consuming, and data collectors do not need special training or expensive equipment, which also makes our method suitable for use in areas where financial or technical means are limited. This approach still gives clear results on the behaviour of recreationists in the study area with minimal disturbance to wildlife and has the advantage of not being biased by subjective or untruthful answers as might be the case in an interview-based study, as discussed by Daniel (2002). Despite the advantages, it was beyond the scope of our study to measure the motivations for people to leave the sampling trails. The finding that the 'direction signs' had most influence on where people left the trail might be an indication that most people intend to reach a landmark and not to deliberately go into a sensitive area. While our analyses included only the conditions within a perception range of $100 \mathrm{~m}$ to both sides of the trail, other factors beyond that range may have added to visitors decisions to pursue offtrail movement. Further research could thus focus on the motivations and targets of the people leaving the trails; for example, if they deliberately went into a wildlife area to view the wildlife or if it was to reach a landmark. The consequential extent and pattern of visitor movements might best be studied using a combined approach of visitor questionnaires and a spatial analysis of the tracks leaving the trail, although additional disturbance by following them into sensitive wildlife areas should be avoided. Moreover, the effectiveness of using the decisive factors that trigger off-trail behaviour for guiding visitors through non-sensitive areas (e.g. by deliberately cutting the vegetation or placing signposts) shall be explored.
Our model reveals the probability of people leaving the trail at a certain location. When means are available, all problematic locations could be subjected to visitor management, in order to achieve a general reduction of recreationists entering wildlife habitats, either directly from the trail or later on their route. Combining the probability distribution with spatial information on key habitats of the target species resulted in a map showing the locations with a high probability of conflict between wildlife and people going off-trail. This considerably narrows down the number of places where management measures should be undertaken, which in turn will facilitate efficient resource use in visitor steering and a consequent reduction in disturbance to wildlife.

Acknowledgements - we would like to thank Friedrich Burghardt, Anna Rummel and Robert Hagen for their help with the data collection and their valuable advice, and Robert Home for language correction.

\section{References}

Amo, L., López, P. \& Martin, J. 2006: Nature-based tourism as a form of predation affects body condition and health state of Podarcis muralis lizards. - Biological Conservation 131: 402-406.

Arlettaz, R., Patthey, P., Baltic, M., Leu, T., Schaub, M., Palme, R. \& Jenni-Eiermann, S. 2007: Spreading freeriding snow sports represent a novel serious threat for wildlife. - Proceedings of the Royal Society, Series B, Biological sciences 274: 1219-1224.

Arnberger, A. \& Hinterberger, B. 2003: Visitor monitoring methods for managing public use pressures in the Danube Floodplains National Park, Austria. - Journal of Nature Conservation 11: 260-267.

Arnold, W., Ruf, T., Reimoser, S., Tataruch, F., Onderscheka, K. \& Schober, F. 2004: Nocturnal hypometabolism as an overwintering strategy of red deer (Cervus elaphus). - American Journal of Physiology. Regulatory, Integrative and Comparative Physiology 268: 174-181.

Baasch, D.M., Tyre, A.J., Millspaugh, J.J., Hygnstrom, S.E. \& Vercauteren, K.C. 2010: An evaluation of three statistical methods used to model resource selection. Ecological Modeling 221: 565-574.

Baltic, M. 2005: Impact of human disturbance on Alpine wildlife in winter: stress, activity and energetics in the endangered Black grouse Tetrao tetrix. - Inauguraldissertation, Universität Bern, Switzerland, 78 pp.

Beale, C.M. \& Monaghan, P. 2004: Human disturbance: people as predation-free predators? - Journal of Applied Ecology 41: 335-343.

Berger, A.L., Della Pietra, S.A. \& Della Pietra, V.J. 1996: A maximum entropy approach to natural language processing. - Computational Linguistics 22: 39-71. 
Braunisch, V., Patthey, P. \& Arlettaz, R. 2011: Spatially explicit modelling of conflict zones between outdoor snowsports and wildlife: delination of winter refuges for declining alpine fauna. - Ecological Applications, pp. 955967.

Braunisch, V. \& Suchant, R. 2006: Das Raufußhühner Bestandesmonitoring der FVA. - Berichte Freiburger Forstliche Forschung 64: 55-67. (In German).

Braunisch, V. \& Suchant, R. 2010: Predicting species distributions based on incomplete survey data: the tradeoff between precision and scale. - Ecography 33: 1-14.

Cassirer, E.F., Freddy, D.J. \& Ables, E.D. 1992: Elk responses to disturbance by cross-country skiers in Yellowstone National Park. - Wildlife Society Bulletin 20: 375-381.

Cessford, G. \& Muhar, A. 2003: Monitoring options for visitor numbers in national parks and natural areas. Journal of Nature Conservation 11: 240-250.

Cole, D.N. 2004: Monitoring and management of recreation in protected areas: the contributions and limitations of science. - In: Sievanen, T., Erkkonen, J., Jokimäki, J., Saarinen, J., Tuulentie, S. \& Virtanen, E. (Eds.); Policies, methods and tools for visitor management. The second International Conference on Monitoring and Management of Visitor Flows in Recreational and Protected areas, Rovaniemi, Finland, pp. 10-17.

Cole, D.N. \& Daniel, T.C. 2003: The science of visitor management in parks and protected areas: from verbal reports to simulation models. - Journal of Nature Conservation 11: 269-277.

Czech, B. 2000: Economic associations among causes of species endangerment in the United States. - Bioscience 50: 593-601.

Daniel, T.C. 2002: Modelling visitor flow from the visitor perspective: the psychology of landscape navigation. - In: Arnberger, A., Brandenburg, C. \& Muhar, A. (Eds.); Monitoring and management of visitor flows in recreational and protected areas. University of Vienna, Vienna, Austria, pp. 159-165.

Della Pietra, S., Della Pietra, V. \& Lafferty, J. 1997: Inducing features of random fields. - IEEE Transactions on Pattern Analysis and Machine Intelligence 19: 1-13.

Dudik, M., Phillips, S.J. \& Schapire, R. 2007: Maximum entropy density estimation with generalized regularization and an application to species distribution modeling. Journal of Machine Learning Research 8: 1217-1260.

Eagles, P.F.J., McCool, S.F. \& Haynes, C.D.A. 2002: Sustainable Tourism in Protected Areas: Guidelines for Planning and Management. - IUCN Gland, Switzerland and Cambridge, UK, 183 pp.

Elith, J., Graham, C.H., Anderson, R.P., Dudik, M., Ferrier, S., Guisan, A., Hijmans, R.J., Huettmann, F., Leathwick, J., Lehmann, A., Li, J., Lohmann, L.G., Loiselle, B.A., Manion, G., Moritz, C., Nakamura, M., Nakazawa, Y., Overton, J.M., Peterson, A.T., Phillips, S.J., Richardson, K., Scachetti-Pereira, R., Schapire, R., Soberón, J., Williams, S., Wisz, M.S. \& Zimmermann, N.E. 2006:
Novel methods improve prediction of species' distributions from occurrence data. - Ecography 29: 129-151.

European Commission 2000: Natura 2000. Managing our heritage. - EU, Luxembourg, 13 pp.

Fernández-Juricic, E. \& Telleria, J.L. 2000: Effects of human disturbance on spatial and temporal feeding patterns of blackbird Turdus merula in urban parks in Madrid, Spain. - Bird Study 47: 13-21.

Geist, V. 1978: Behaviour. - In: Schmidt, J.L. \& Gilbert, D.L. (Eds.); Big game of North America: ecology and management. Stackpole Books, Harrisburg, Pennsylvania, USA, $494 \mathrm{pp}$.

Hennig, S. \& Künzl, M. 2011: Applying Integrated Nature Conservation Management: Visitor Management and Monitoring of Winter Recreation Activities Focusing Grouse Species in Berchtesgaden National Park. - In: Zhelezov, G. (Ed.); Sustainable Development in Mountain Regions, Southeastern Europe. Springer Verlag, New York, New York, USA, pp. 239-254.

Hosmer, D.W.J. \& Lemeshow, S. 2000: Applied Logistic Regression. 2nd edition. - John Wiley \& Sons, New York, New York, USA, 392 pp.

Ingold, P. 2005: Freizeitaktivitäten im Lebensraum der Alpentiere. Konfliktbereiche zwischen Mensch und Tier. Mit einem Ratgeber für die Praxis. - Haupt verlag, Bern, Switzerland, 516 pp. (In German).

Jayakody, S., Sibbald, A.M., Gordon, I.J. \& Lambin, X. 2008: Red deer Cervus elaphus vigilance behaviour differs with habitat and type of human disturbance. - Wildlife Biology 14(1): 81-91.

Jaynes, E.T. 1957: Information theory and statistical mechanics. - Physical Review 106: 620-630.

Jepsen, E.P.B., Keane, J.J. \& Holly, B.E. 2011: Winter distribution and conservation status of the Sierra Nevada Great Gray owl. - Journal of Wildlife Management 75: 1678-1687.

Keirle, I. \& Stephens, M. 2004: Do walkers stay on footpaths? An observational study of Cwm Idwal in the Snowdonia National Park. - In: Sievanen, T., Erkkonen, J., Jokimäki, J., Saarinen, J., Tuulentie, S. \& Virtanen, E. (Eds.); Policies, methods and tools for visitor management: The second International Conference on Monitoring and Management of Visitor Flows in Recreational and Protected areas, Rovaniemi, Finland, pp. 143-148.

Miller, S.G., Knight, R.L. \& Miller, C.K. 2001: Wildlife responses to pedestrians and dogs. - Wildlife Society Bulletin 29: 124-132.

Moss, R. \& Watson, A. 1984: Maternal nutrition, egg quality and breeding success of Scottish ptarmigan Lagopus mutus. - Ibis 126: 212-220.

Müllner, A., Linsenmair, K.E. \& Wikelski, M. 2004: Exposure to ecotourism reduces survival and affects stress response in hoatzin chicks (Opisthocomus hoazin). Biological Conservation 118: 549-558.

Nisbitt, R.E. \& Wilson, T.D. 1977: Telling more than we can know: verbal reports on mental processes. - Psychological Review 84: 231-259. 
Park, L.O., Manning, R.E., Marion, J.L., Lawson, S.R. \& Jacobi, C. 2008: Managing visitor impacts in parks: A multi-method study of the effectiveness of alternative management practices. - Journal of Park and Recreation Administration 26: 97-121.

Patthey, P., Wirthner, S., Signorell, N. \& Arlettaz, R. 2008: Impact of outdoor winter sports on the abundance of a key indicator species of alpine ecosystems. - Journal of Applied Ecology 45: 1704-1711.

Phillips, S.J., Anderson, R.P. \& Schapire, R.E. 2006: Maximum entropy modeling of species geographic distributions. - Ecological Modelling 190: 231-259.

Phillips, S.J. \& Dudik, M. 2008: Modeling of species distributions with Maxent: new extensions and a comprehensive evaluation. - Ecography 31: 161-175.

Reimoser, F. 1988: Weniger Wildschäden durch Ruhezonen? - Österreichische Forstzeitung 99: 24-25. (In German).

Stankowich, T. 2008: Ungulate flight responses to human disturbance: a review and meta-analysis. - Biological Conservation 141: 2159-2173.

Storch, I. 2000: Conservation status and threats to grouse worldwide: an overview. - Wildlife Biology 6(4): 195-204.

Storch, I. 2007a: Conservation status of grouse worldwide: an update. - Wildlife Biology 13(Suppl. 1): 5-12.

Storch, I. 2007b: Grouse: Status Survey and Conservation Action Plan 2006-2010. - Gland, Switzerland: IUCN and Fordingbridge, UK: World Pheasant Association, 114 pp.

Suchant, R., Baritz, R. \& Braunisch, V. 2003: Wildlife Habitat analysis: a multidimensional habitat management model. - Journal for Nature Conservation 10: 253-268.

Suchant, R., Burghardt, F. \& Gerecke, K.L. 2008: Rotwild im Südschwarzwald. Konzeption eines integrativen Rotwild-Managements. - Projektgruppe Rotwild, 39 pp. (Available at: http://www.waldwissen.net/ wald/wild/management/fva_rotwildkonzeption/fva_ gesamtbroschuere_rotwild_konzeption_schwarzwald. pdf) (In German).

Swets, J.A. 1988: Measuring the accuracy of diagnostic systems. - Science 240: 1285-1293.

Taylor, A.R. \& Knight, R.L. 2003: Wildlife responses to recreation and associated visitor perceptions. - Ecological Applications 13: 951-963.

Thiel, D., Menoni, E., Brenot, J.F. \& Jenni, L. 2007: Effects of recreation and hunting on flushing distance of capercaillie. - Journal of Wildlife Management 71: 1784-1792.
Thiel, D., Jenni-Eiermann, S., Braunisch, V., Palme, R. \& Jenni, L. 2008: Ski tourism affects habitat use and evokes a physiological stress response in capercaillie Tetrao urogallus: a new methodological approach. - Journal of Applied Ecology 45: 845-853.

Türk, S., Jacob, E., Krämer, A. \& Roth, R. 2004: Outdoor recreation activities in nature protection areas: situation in Germany. - In: Sievanen, T., Erkkonen, J., Jokimäki, J., Saarinen, J., Tuulentie, S. \& Virtanen, E. (Eds.); Policies, methods and tools for visitor management: The second International Conference on Monitoring and Management of Visitor Flows in Recreational and Protected areas, Rovaniemi, Finland, pp. 171-177.

UN 1999: Report of the Secretary-General on tourism and environmental protection. - Commission on Sustainable Development. United Nations. (E/CN.17/1999/5/Add.3), $11 \mathrm{pp}$.

UN 2001: Report of the Secretary-General on the sustainable development of tourism. - Commission on Sustainable Development acting as the preparatory committee for the World Summit on Sustainable Development. United Nations. (E/CN.17/2001/PC/21), 4 pp.

UNEP 2007: Tourism and Mountains: A Practical Guide to Managing the Environmental and Social Impacts of Mountain Tours. - United Nations Environmental Program, $51 \mathrm{pp}$.

Watson, A. \& Moss, R. 2004: Impacts of ski-development on ptarmigan (Lagopus mutus) at Cairn Gorm, Scotland. Biological Conservation 116: 267-275.

Watson, A.E., Cole, D.N., Turner, D.L. \& Reynolds, P.S. 2000: Wilderness recreation use estimation: a handbook of methods. - Rocky Mountain Research Station. Ogden, Utah, USA, RMRS-GTR-56, 198 pp.

Wiley, E.O., McNyset, K.M., Peterson, A.T., Robins, C.R. \& Stewart, A.M. 2003: Niche modelling and geographic range predictions in the marine environment using a machine-learning algorithm. - Oceanography 16: 120-127.

Yarmoloy, C., Bayer, M. \& Geist, V. 1988: Behavior responses and reproduction of mule deer (Odocoileus hemionus) does, following experimental harassment with an all-terrain vehicle. - Canadian Field-Naturalist 102: 425-429.

Yorio, P., Frere, E., Gandini, P. \& Schiavini, A. 2001: Tourism and recreation at seabird breeding sites in Patagonia, Argentina: current concerns and future prospects. - Bird Conservation International 11: 231-245. 